J. Lake Sci.(湖泊科学), 2008, 20(3): 271-276

http://www.jlakes.org. E-mail: jlakes@niglas.ac.cn

(C)2008 by Journal of Lake Sciences

\title{
养殖污染水体-沉积物中磷的化学行为*
}

\author{
米玮洁 ${ }^{1}$, 周易勇 ${ }^{2}$, 朱端卫 ${ }^{1}$, 杨旺赣 ${ }^{1}$ \\ (1: 华中农业大学植物营养与生态环境研究室, 武汉 430070) \\ (2: 中国科学院水生生物研究所, 武汉 430072)
}

摘 要: 通过受猪场污水影响的池塘和鱼塘水生生态系统中表层水-沉积物的磷含量、磷吸附能力比较, 了解猪场污水、鱼塘 养殖对表层水-沉积物系统磷行为的影响. 结果表明, 猪场污水排放和鱼塘养殖都会明显增加水体中溶解性反应磷(DRP)和溶 解性有机磷 (DOP)的含量, 从 DRP、DOP、PP 3 种形态磷在总磷中所占的比例来看, DRP 是水体中主要增加的磷含量. 猪场污 水排放对水体中磷的增加作用比鱼塘养殖更剧烈一些, 猪粪是水体中磷的主要来源. 但是猪场污水排放对沉积物中不同形态 磷含量的影响不明显, 这可能与水体中磷的存在形态和转化时间有关. 鱼塘养殖增加了沉积物中有机质、Fe-P、Al-P 和总无 机磷含量, 增加了沉积物对磷的最大吸附容量, 但是对磷的吸附能力却有所降低, 进而增加了沉积物中磷向上覆水释放的可能. 关键词: 养猪场污水; 鱼塘养殖; 磷; 磷形态; 磷吸附容量

\section{The phosphorous chemical behavior in water-sediment polluted by sewage of manure and aquiculture}

\author{
MI Weijie ${ }^{1}$, ZHOU Yiyong ${ }^{2}$, ZHU Duanwei ${ }^{1} \&$ YANG Wanggan ${ }^{1}$ \\ (1: Laboratory of Plant Nutrition and Ecological Environment Research, Huazhong Agricultural University, Wuhan 430070, \\ P.R.China) \\ (2: Institute of Hydrobiology, Chinese Academy of Sciences, Wuhan 430072, P.R.China)
}

\begin{abstract}
According to compare the content of phosphorus (P) fraction, P sorption ability of water-sediment in ponds polluted by sewage from a hoggery and a rearing-pond, the influences of sewage from hoggery and fishery on $\mathrm{P}$ behavior in water-sediment system were studied. The results indicated that sewage from hoggery and fishery could significantly increase P contents in water, and sewage from hoggery increased more significantly dissolved $\mathrm{P}$ in water than fishery. Sewage from hoggery had no significant influence on sediment $\mathrm{P}$ concentration and $\mathrm{P}$ sorption properties, whereas fishery could significantly increase total inorganic $\mathrm{P}, \mathrm{Fe}$ bound $\mathrm{P}$ (Fe-P) in sediment and maximum $\mathrm{P}$ sorption capacity and decrease $\mathrm{P}$ absorptive capability of sediment. The P sorption properties of sediment had some relationship with organic matter content in sediment.
\end{abstract}

Keywords: Sewage from hoggery; aquiculture; P; P fractions; P sorption capacity

磷常为水体生产力的关键限制性营养，外源磷的输人将加速湖泊富营养化过程，然而外源排放减少 之后, 沉积物蓄积的磷释放使水体仍维持较高的磷营养水平 ${ }^{[1]}$. 土壤施用粪肥会增加土壤磷含量, 对土 壤中磷向地表径流流失产生影响, $\mathrm{F}$ 影响表层水中的磷含量, 是引起水体富营养化的因素之一 ${ }^{[2-4]}$. 禽畜 粪便向水生生态系统中的直接排放会导致沉积物和水体中的磷含量明显升高 ${ }^{[5]}$. 土壤施用有机粪肥会改 变土壤中不同形态磷含量, 增加土壤中磷累积, 其中分解的有机酸的作用会对土壤吸附磷的能力产生影响 ${ }^{[6]}$. 然而, 养殖污水的排放对水体中磷含量以及沉积物中各形态磷含量和磷吸附能力有何影响, 相关研究较 少. 本文从沉积物-表层水系统的角度比较了养猪场污水排放、鱼塘养殖对表层水中不同形态磷含量、沉 积物磷分级形态的影响, 进而研究沉积物对磷的吸附能力与沉积物中有机质含量的关系.

* 中国科学院知识创新工程重要方向项目(KZCX2-YW-426)和国家自然科学基金项目(20577013)联合资助. 2007-04-06 收稿; 2007-08-20 收修改稿. 米玮洁, 女, 1980 年生, 博士研究生; E-mail: miweijie@webmail.hzau.edu.cn. 



\section{1 材料与方法}

\section{1 野外观测与采样}

作为供试水域的野芷湖 $\left(1\right.$ 号样点 $\left.114^{\circ} 20^{\prime} 05.53^{\prime \prime} \mathrm{E}, 30^{\circ} 28^{\prime} 18.86^{\prime \prime} \mathrm{N}\right)$ 位于武昌南郊, 其东北方建有一猪 场. 猪场建于 2001 年, 年养猪量 300 头, 年产猪粪约 $3 t, 95 \%$ 固体猪粪干收运出猪场处理, 剩余猪粪每天 用水冲洗, 冲洗废水沉淀后未经处理直接排到一个面积约 $100 \mathrm{~m}^{2}$, 水深约 $1 \mathrm{~m}$ 的小池塘 (2 号样点 $\left.114^{\circ} 20^{\prime} 23.79^{\prime \prime} \mathrm{E}, 30^{\circ} 28^{\prime} 11.68^{\prime \prime} \mathrm{N}\right) .2$ 号样点西边距离 $2 \mathrm{~m}$ 处有一个正在使用的鱼塘( 3 号样点 $114^{\circ} 20^{\prime} 10.66^{\prime \prime} \mathrm{E}$, $30^{\circ} 28^{\prime} 23.01^{\prime \prime} \mathrm{N}$ ), 鱼塘面积约 $300 \mathrm{~m}^{2}$, 水深约 $1 \mathrm{~m}$. 鱼塘每年抽水捕鱼, 但是从未清过塘. 2 号与 3 号样点位 于 1 号样点的北方, 3 号与 1 号点之间有一水闸相通, 2 号点与 $1 、 3$ 号点均不连通. 3 个取样点所处地势平 坦, 无地表径流产生.

水样采集: 2002 年 $1-5$ 月用普通采水器每半个月(每月 5 日、 20 日)采集一次表层水样. 泥样采集: 2002 年 3 月用彼得森抓泥器采集沉积物. 猪粪采集: 用四分法采集混合粪样.

\section{2 样品制备}

水样制备：将水样取回实验室摇匀后一部分立即通过 $0.45 \mu \mathrm{m}$ 的滤膜过滤，将原水样和过滤水样置于 $4^{\circ} \mathrm{C}$ 冰箱中一个星期内测定; 泥样制备: 将泥样至于阴凉处推开, 风干后粉碎, 分别过 60 目、100 目篎备 用; 猪粪样制备: 将猪粪样置于烘箱中, 于 $65^{\circ} \mathrm{C}$ 烘干后, 过 20 目篮.

\section{3 分析方法}

1.3.1 水体中 DRP、DTP、TP 的测定 溶解态反应性磷(Dissolved Reactive Phosphorus, DRP)的测定：过 $0.45 \mu \mathrm{m}$ 滤膜的水样直接测定 DRP 的浓度 ${ }^{[7]}$. 溶解态磷 (Dissolved Total Phosphorus, DTP)、总磷(Total Phosphorus, TP) 的测定: 分别取过 $0.45 \mu \mathrm{m}$ 的水样和原水样于三角瓶中, 加人三酸混合液 $\left(\mathrm{HNO}_{3}: \mathrm{HClO}_{4}: \mathrm{H}_{2} \mathrm{SO}_{4}=7: 2: 1\right)$ 消解, 然后无损转移至容量瓶中, 用钿锑抗比色法测定. 溶解态有机磷 (Dissolved Organic Phosphorus, DOP)、颗粒态磷(Particular Phosphorus, PP)的计算: DOP = DTP - DRP; $\mathrm{PP}=\mathrm{TP}-\mathrm{DTP}$.

1.3.2 沉积物对磷的吸附能力的测定 在 $2.5 \mathrm{~g}$ 沉积物中加人 $50 \mathrm{ml}$ 标准磷溶液(用 $0.02 \mathrm{~mol} / \mathrm{L} \mathrm{KCl}$ 配制) 和适 量三氯甲烷, 于 $25^{\circ} \mathrm{C}$ 振荡 $24 \mathrm{~h}$ (转速 200 转 $/ \mathrm{min}$ ). 等温曲线的初始浓度分别为 $0.78 、 1.55 、 2.33 、 3.10$ 、 $4.65 、 6.20 、 12.40 、 18.60 、 24.80 、 31.00 \mu \mathrm{g} / \mathrm{ml}$. 根据 Langmuir 单分子等温吸附方程测定最大吸附容量 $X m$ 和吸附强度 $K^{[8]}$.

\subsection{3 沉积物中有机质的测定 $\mathrm{K}_{2} \mathrm{Cr}_{2} \mathrm{O}_{7}$ 容量法 ${ }^{[9]}$.}

1.3.4 沉积物无机磷形态分级体系 依次用 $1 \mathrm{~mol} / \mathrm{L} \mathrm{NH}_{4} \mathrm{Cl} 、 0.5 \mathrm{~mol} / \mathrm{L} \mathrm{NH}_{4} \mathrm{~F} 、 0.5 \mathrm{~mol} / \mathrm{L} \mathrm{NaOH} 、 0.3 \mathrm{~mol} / \mathrm{L}$ 柠 檬酸钠和连二亚硫酸钠、 $0.5 \mathrm{~mol} / \mathrm{L} \mathrm{H}_{2} \mathrm{SO}_{4}$ 连续浸提沉积物, 将沉积物中的无机磷分为水溶性磷、 $\mathrm{Al}-\mathrm{P} 、$ Fe-P、闭蓄态磷 $(\mathrm{O}-\mathrm{P}) 、 \mathrm{Ca}-\mathrm{P}^{[9]}$.

1.3.5 猪粪中磷的分级体系依次用 $\mathrm{H}_{2} \mathrm{O} 、 0.5 \mathrm{~mol} / \mathrm{L} \mathrm{NaHCO}_{3} 、 0.1 \mathrm{~mol} / \mathrm{L} \mathrm{NaOH} 、 1.0 \mathrm{~mol} / \mathrm{L} \mathrm{HCl}$ 连续浸提 供试猪粪中的磷 ${ }^{[10]}$ : 其中能被水浸提出的磷为水溶性磷; 能被 $0.5 \mathrm{~mol} / \mathrm{L} \mathrm{NaHCO}_{3}$ 浸提出的磷为可被植 物吸收的磷; 能被 $0.1 \mathrm{~mol} / \mathrm{L} \mathrm{NaOH}$ 浸提出的磷为可被藻类吸收的磷; 能被 $1.0 \mathrm{~mol} / \mathrm{L} \mathrm{HCl}$ 浸提出的磷为 酸溶性磷.

\section{2 结果与分析}

\section{1 水体中各形态磷含量}

不同采样点各形态磷随时间变化的趋势不同(表 1). 不同时间 2 号采样点 TP、DRP、DTP、DOP 浓 度均明显高于 1 号与 3 号采样点的相应值, 猪场可将大量溶解态磷富集于接受其污水排放的池塘. 由于 每年换水使得鱼塘水体中各形态磷含量增加的趋势没有猪场污水表现明显, 但是鱼塘养殖仍使得 3 号采 样点各形态磷浓度明显高于野芷湖( 1 号采样点)的相应值. 故家畜与水产养殖废水均能明显提高地表水 中溶解态磷的浓度. 
表 1 不同时间各采样点磷形态浓度 $(\mathrm{mg} / \mathrm{L})(2002$ 年 $1-5$ 月) *

Tab.1 Content of DRP, DOP, DTP, PP and TP in sampled water from Jan. to May, 2002 (mg/L)

\begin{tabular}{|c|c|c|c|c|c|c|c|c|c|c|}
\hline \multirow{2}{*}{$\mathrm{P}$ 形态 } & \multirow{2}{*}{ 样点 } & \multicolumn{9}{|c|}{ 取样时间(月-日) } \\
\hline & & $01-05$ & $01-20$ & $02-05$ & $02-20$ & 03-05 & $03-20$ & 04-05 & $05-05$ & $05-20$ \\
\hline \multirow[t]{3}{*}{ DRP } & 1 & $\mathrm{ND}^{*}$ & 0.0181 & 0.0510 & 0.0350 & 0.0240 & 0.0150 & 0.0220 & 0.0160 & 0.0420 \\
\hline & 2 & 4.039 & 3.885 & 4.509 & 5.630 & 3.246 & 3.348 & 4.060 & 2.778 & 2.082 \\
\hline & 3 & 0.0529 & 0.1854 & 0.0864 & 0.1704 & 0.4613 & 0.1832 & 0.2592 & 0.1331 & 0.1500 \\
\hline \multirow[t]{3}{*}{ DOP } & 1 & 0.1029 & 0.3899 & 0.2240 & 0.5402 & 0.4064 & 0.2301 & 0.6530 & 0.8941 & 0.3311 \\
\hline & 2 & 6.311 & 10.39 & 9.616 & 11.37 & 6.164 & 4.752 & 3.540 & 1.937 & 0.9341 \\
\hline & 3 & 0.4227 & 0.4070 & 0.2641 & 0.5804 & 0.4022 & 0.3923 & 1.1914 & 0.9672 & 0.3521 \\
\hline \multirow[t]{3}{*}{ DTP } & 1 & 0.1029 & 0.4080 & 0.2750 & 0.5752 & 0.4304 & 0.2451 & 0.6750 & 0.9101 & 0.3731 \\
\hline & 2 & 10.35 & 14.28 & 14.13 & 17.00 & 9.410 & 8.100 & 7.600 & 4.715 & 3.016 \\
\hline & 3 & 0.4756 & 0.5924 & 0.3502 & 0.7508 & 0.8635 & 0.5755 & 1.451 & 1.100 & 0.5021 \\
\hline \multirow[t]{3}{*}{ PP } & 1 & 0 & 0.0362 & 0.2745 & 0.1500 & 0.1447 & 0.1299 & 0.0504 & 0.1429 & 0.1291 \\
\hline & 2 & 0.3000 & 0.6950 & 0.8250 & 0.6000 & 0.3350 & 0.4000 & 0.1500 & 0.1900 & 0.1299 \\
\hline & 3 & 0.0948 & 0.3337 & 0.4494 & 0.3742 & 0.3865 & 0.7495 & 0.1244 & 0.2377 & 0.2579 \\
\hline \multirow[t]{3}{*}{$\mathrm{TP}$} & 1 & 0.1029 & 0.4442 & 0.5495 & 0.7252 & 0.5751 & 0.3751 & 0.7254 & 1.053 & 0.5022 \\
\hline & 2 & 10.65 & 14.97 & 14.95 & 17.60 & 9.745 & 8.500 & 7.750 & 4.905 & 3.146 \\
\hline & 3 & 0.5704 & 0.9261 & 0.7995 & 1.125 & 1.250 & 1.325 & 1.575 & 1.338 & 0.7600 \\
\hline
\end{tabular}

* ND 表示未检测出.

DRP、DOP 和 PP 三者在 TP 中所占的比例在 3 个样点水体中也表现出明显的差异： 2 号点水体中的 $\mathrm{DRP} / \mathrm{TP}$ 明显高于的 $1 、 3$ 号点水体, 而 PP/TP 明显低于 $1 、 3$ 号点水体(图 1). 这表明猪场污水的排放导 致水体中 DRP、DOP 含量都有所增加, 因此猪场污水主要增加的是水体中的溶解态磷. 3 号点鱼塘表层水 中 PP 占有较高的比例, 而 1 号点野芷湖表层水中则是 DOP 占有优势.
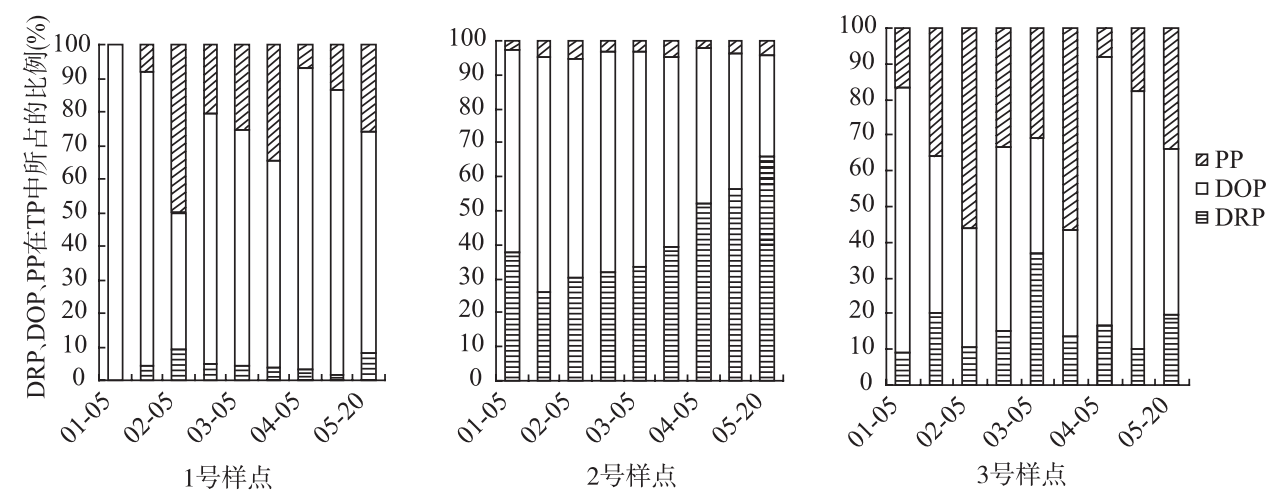

图 1 不同取样时间各样点水体中 DRP、DOP、PP 在 TP 中所占的比例(2002 年 1-5 月)

Fig.1 Content of DRP, DOP and PP in proportion to TP of sampled water from Jan. to May, 2002

\section{2 猪粪磷分级}

从供试的猪粪磷分级结果可以看出(表 2), 猪粪中能被 $\mathrm{H}_{2} \mathrm{O} 、 0.5 \mathrm{~mol} / \mathrm{L} \mathrm{NaHCO} 、 0.1 \mathrm{~mol} / \mathrm{L} \mathrm{NaOH}$ 和 $1.0 \mathrm{~mol} / \mathrm{L} \mathrm{HCl}$ 浸提出的无机磷含量分别为 $4.19 \mathrm{~g} / \mathrm{kg} 、 4.28 \mathrm{~g} / \mathrm{kg} 、 1.69 \mathrm{~g} / \mathrm{kg}$ 和 $7.28 \mathrm{~g} / \mathrm{kg}$ ，其中代表生物有效态磷 的前 3 种形态磷含量之和高达 $10.2 \mathrm{~g} / \mathrm{kg}$. 猪粪中水溶性无机磷占浸提出的总无机磷的 $24.04 \%$, 而 $\mathrm{H}_{2} \mathrm{O}$ 、 $\mathrm{NaHCO}_{3} 、 \mathrm{NaOH}$ 浸提出的无机磷占浸提出的总无机磷的 $58.26 \%$, 可见猪粪中的水溶性磷占有一定比例. 
表 2 猪粪中磷分级

Tab.2 Fraction of phosphorus in pig manure

\begin{tabular}{lcc}
\hline 提取剂 & $\begin{array}{c}\text { 无机磷 }(\mathrm{Pi}) \\
(\mathrm{g} / \mathrm{kg})\end{array}$ & $\begin{array}{c}\text { 总磷 }(\mathrm{TP}) \\
(\mathrm{g} / \mathrm{kg})\end{array}$ \\
\hline $\mathrm{H}_{2} \mathrm{O}$ & 4.19 & 13.13 \\
$0.5 \mathrm{~mol} / \mathrm{L} \mathrm{NaHCO}_{3}$ & 4.28 & 23.02 \\
$0.1 \mathrm{~mol} / \mathrm{L} \mathrm{NaOH}$ & 1.69 & 8.73 \\
$1.0 \mathrm{~mol} / \mathrm{L} \mathrm{HCl}$ & 7.28 & 44.84 \\
\hline
\end{tabular}

\section{3 沉积物中磷含量和形态}

从表 3 可以看出, 鱼塘养殖 4 年使得 3 号 (鱼塘)沉积物中水溶磷 $(\mathrm{Psol}) 、$ 铝磷 $(\mathrm{Al}-\mathrm{P})$ 、铁 磷(Fe-P)和总无机磷(TPi)含量明显高于 1 号和 2 号沉积物. 3 号沉积物中总磷含量较高可能 与其水体中高 PP 含量以及 PP 向沉积物中沉 积有关. 与野芷湖沉积物 (1 号)相比, 受养猪 场污水影响的 2 号沉积物中含有较高的 Fe-P 含量, 较低的水溶磷 $(\mathrm{Psol})$ 和闭蓄态磷 $(\mathrm{O}-\mathrm{P})$ 含

量. 1 号、 2 号沉积物中 TPi 含量相似, 因此接纳猪场污水排放一年的条件下, 猪场污水排放对沉积物中无机 磷含量并没有显著影响, 这可能与 2 号点水体中的 P 主要以溶解态存在有关. 3 个样点沉积物中 Fe-P、Al-P 含量都占主导地位. 3 个样点的供试沉积物中钲磷含量没有表现出明显差异, 即与野芷湖沉积物相比, 养猪 场污水的排放或鱼塘养殖对沉积物中钙磷形态都没有显著增加. 而 2 号和 3 号样点沉积物中的 O-P 含量明 显低于野芷湖(1 号样点)沉积物, 因此猪场污水排放和鱼塘养殖均能降低沉积物中闭蓄态磷的含量.

表 3 各样点沉积物中的磷分级*

Tab.3 Fraction of phosphorus in sediments of all samples

\begin{tabular}{ccccccc}
\hline \multirow{2}{*}{ 样点号 } & \multicolumn{7}{c}{ 不同磷形态 $(\mathrm{mg} / \mathrm{kg})$} \\
\cline { 2 - 7 } & 水溶 P(Psol) & Al-P & Fe-P & O-P & Ca-P & TPi \\
\hline 1 & $2.79^{\mathrm{b}}$ & $66.04^{\mathrm{b}}$ & $198.3^{\mathrm{c}}$ & $60.78^{\mathrm{a}}$ & $48.79^{\mathrm{a}}$ & $377.4^{\mathrm{b}}$ \\
2 & $1.85^{\mathrm{c}}$ & $58.42^{\mathrm{b}}$ & $236.8^{\mathrm{b}}$ & $32.14^{\mathrm{b}}$ & $46.90^{\mathrm{a}}$ & $378.4^{\mathrm{b}}$ \\
3 & $5.99^{\mathrm{a}}$ & $122.6^{\mathrm{a}}$ & $455.6^{\mathrm{a}}$ & $34.59^{\mathrm{b}}$ & $44.55^{\mathrm{a}}$ & $668.0^{\mathrm{a}}$ \\
\hline
\end{tabular}

*不同上标小写字母表示 $5 \%$ 差异.

\section{4 沉积物磷吸附性状}

在对供试沉积物的磷形态分级研究的同时, 本文对沉积物进行了磷的等温吸附研究. 表 4 中列出了供试 沉积物的 Langmuir 吸附曲线的最大吸附容量和吸附常数等结果, 从中可以看出, 1 号和 2 号样点的沉积物对磷 的最大吸附容量和吸附常数以及总磷含量都没有表现出明显的差异. 即与野芷湖沉积物相比, 猪场污水排放 对池塘沉积物最大磷吸附容量、吸附常数没有明显影响. 鱼塘 3 号样点沉积物有机质含量明显高于其它 2 个 样点沉积物, 此时, 沉积物对磷的吸附性质发生了很大变化, 不仅其无机磷总量最高, 磷的最大吸附量也最高, 但沉积物对磷进一步的吸附能力减弱, 表现为沉积物的磷吸附常数明显低于其他两种沉积物. 沉积物中 OM 含量对沉积物磷吸附表现出一定的影响, 即沉积物中的有机质含量越高, 磷含量越高, 则沉积物对上覆水中

表 4 供试沉积物有机质含量及其磷吸附性能*

Tab.4 Organic matter, TP and the sorption properties of sediments to phosphorous

\begin{tabular}{llll}
\hline 样点 & 1 & 2 & 3 \\
\hline 最大吸附容量 $X m(\mu \mathrm{g} / \mathrm{g})$ & $715.13^{\mathrm{b}}$ & $872.16^{\mathrm{ab}}$ & $992.87^{\mathrm{a}}$ \\
吸附常数 $K$ & $0.993^{\mathrm{a}}$ & $1.054^{\mathrm{a}}$ & $0.524^{\mathrm{b}}$ \\
有机质含量 & $2.93 \%^{\mathrm{b}}$ & $3.24 \%^{\mathrm{b}}$ & $6.17 \%^{\mathrm{a}}$ \\
TPi $(\mu \mathrm{g} / \mathrm{g})$ & $376.66^{\mathrm{b}}$ & $376.11^{\mathrm{b}}$ & $663.38^{\mathrm{a}}$ \\
\hline
\end{tabular}

*不同上标小写字母表示 $5 \%$ 差异.
磷的吸附容量越大, 但吸附能力越弱.

\section{3 讨论}

\section{1 猪场污水排放、鱼塘养殖对供试水体中 各形态磷含量的影响}

有研究表明, 粪肥在土壤中施用后, 水 土流失会导致地表水中各形态磷含量增加, 其中家畜粪便的施用会使地表水中 DRP 的含 量由背景值 $(0.4 \mathrm{mg} / \mathrm{L})$ 很快增加到 $18 \mathrm{mg} / \mathrm{L}$ 以 上 $^{[11]}$, 而且溶解性磷含量增加的幅度要大于 总磷含量增加的幅度 ${ }^{[12]}$. 这与本研究中得到的猪场污水的排放增加了水体中各形态磷含量, 而且主要增 加的是水体中溶解态磷的结果相一致.

猪粪是导致水体高磷的主要外源污染. 土壤中总磷的含量范围一般为 $0.44-0.85 \mathrm{~g} / \mathrm{kg}^{[13]}$, 猪粪中的总 
磷含量高达 $16.2 \mathrm{~g} / \mathrm{kg}$, 而且猪粪中磷的赋存形态主要为生物有效态 ${ }^{[14]}$. 按照一万头猪每年产生 $100 \mathrm{t}$ 猪粪 的标准来计算, 本研究中猪场每年能产生 $3 \mathrm{t}$ 猪粪, $5 \%$ 剩余猪粪被水冲洗, 则猪粪中每年有 $628.5 \mathrm{~g}$ 无机磷 能被水浸提出来. 因此猪粪中高含量的水溶态磷是导致接受猪场污水的池塘水体高磷的主要来源.

\section{2 猪场污水排放、鱼塘养殖对沉积物中磷含量和形态的影响}

猪场污水排放一年时间内, 猪场污水对池塘沉积物中的各形态磷含量的影响并不明显, 这表明养猪 场污水排出的磷向沉积物中转化需要一定的时间完成. 粪肥在土壤中施用后, 粪肥中的磷向土壤中的转 化形态也受到时间的影响 ${ }^{[15]}$.

围塘养殖沉积物中无机磷含量在总磷中占有很高的比例, 而且围塘养殖能明显提高沉积物中的总磷 含量 ${ }^{[16]}$. 与之相一致, 本研究中养殖鱼塘沉积物中总无机磷含量明显高于其他两个样点, 主要表现在对 沉积物中 Fe-P 、Al-P 含量的增加. 王永和等 ${ }^{[17]}$ 、尹金来等 ${ }^{[18]}$ 认为施用猪粪能显著提高土壤无机磷组分，主 要是增加石灰性土壤中的 Ca-P 含量, 其 Al-P、Fe-P 含量也有一定的提高. 而 Leinweber 则认为, 粪肥施 人土壤后, 其中的磷主要与土壤中氧化物和腐殖酸物质发生反应转化成 Fe-P 和残留态磷 ${ }^{[14]} .3$ 个样点沉 积物中 Fe-P、Al-P 含量都占主导地位，而沉积物中 Fe-P、Al-P 都具有潜在的活化能力 ${ }^{[19-21]}$. 因此, 沉积 物中磷具有向上覆水中释放的趋势.

此外, 粪肥施用对土壤中不同形态的磷具有不同的活化和固定作用. 有机肥在分解过程中产生的有 机酸对 Al-P、Fe-P 的溶解效果好, 主要活化的是土壤中的 Al-P、Fe-P ${ }^{[22]}$. 但也有观点认为动物粪肥的有 机酸分子量大, 难与土壤中的 $\mathrm{Al}$ 发生反应, 所以 $\mathrm{Al}-\mathrm{P}$ 是难被活化的一种形态 ${ }^{[23]}$. 但是从鱼塘沉积物的 Fe-P、Al-P 含量的明显增加可以看出，鱼塘养殖对沉积物中磷的活化作用明显小于沉积物对磷的固定作 用, 最终使得沉积物总无机磷含量明显增加.

尽管有研究认为有机肥施用对土壤中的 Ca-P 形态有影响: 一方面表现为增加土壤中的 Ca-P 含量 ${ }^{[17-18]}$, 另一方面表现为有机肥对土壤中的钲磷具有活化作用 ${ }^{[22]}$, 但是本研究中 3 个样点供试沉积物中钙磷含量 没有表现出明显差异. 一方面可能是因为沉积物中钙盐对磷的吸附作用达到饱和, 使得沉积物中增加的 磷没有转化为 Ca-P 形态, 另一方面也可能是因为钻磷形态可能是一种比较稳定的形态, 不易被转化. 而 还原性强的沉积物中的 O-P 形态可能是易活化的磷形态, 猪场污水排放、鱼塘养殖可能会活化沉积物中 O-P 转化为其他磷形态. 章永松等研究有机肥对土壤不同形态无机磷的活化作用时也发现淹水条件下有 机肥对土壤中的闭蓄态磷有较强的活化作用 ${ }^{[22]}$.

\section{3 猪场污水排放、鱼塘养殖对沉积物磷吸附的影响}

一般研究都认为粪肥在土壤中的施用会降低土壤的最大吸附容量和吸附能力 ${ }^{[24]}$, 降低土壤对磷的吸 附, 增加磷的解吸, 降低土壤对无机磷的固定 ${ }^{[6]}$. Halford 等 ${ }^{[25]}$ 的研究也表明, 长期施用粪肥会降低土壤对 磷的吸附容量和强度, 但是粪肥的施用若增加了土壤碳和铁的含量, 则可能会增加土壤对磷的吸附容量. 因此土壤碳/有机质含量对其磷吸附特性有一定的影响, 但是其影响在不同的研究中表现不太一致. 一种 观点认为沉积物中 $\mathrm{OM}$ 含量增加会降低沉积物对磷的吸附能力和吸附容量: 沉积物对上覆水中溶解性磷 的吸附能力与底质中有机质呈负相关关系 ${ }^{[26]}$, 沉积物对磷的最大吸附量与有机质和总磷含量也呈负相关 关系 ${ }^{[27]}$. 但是 Villapado 等 ${ }^{[28]}$ 的研究却表明由于有机质增加了土壤颗粒与 $\mathrm{Fe} 、 \mathrm{Al} 、 \mathrm{Ca}$ 离子结合的能力, 而 土壤对磷的吸附是土壤中柠檬酸钠-连二亚硫酸钠-碳酸氢钠 $(\mathrm{CDB})$ 提取态 $\mathrm{Fe}$ 和草酸提取态 $\mathrm{Al} 、 \mathrm{Fe}$ 的共同 作用, 所以有机质含量与磷吸附呈正相关. 在本研究中, 鱼塘养殖通过鱼覀投放、鱼粪便对沉积物中有机 质含量产生影响进而影响沉积物对磷的吸附能力.

\section{4 参考文献}

[1] Boström B, Andersen JM, Fleischer S et al. Exchange of phosphorus across the sediment-water interface. Hydrobiologia, 1988, 170: $229-244$.

[2] Ginting D, Moncrief JF, Gupta SC et al. Interaction between manure and tillage system on phosphorus uptake and runoff losses. Journal of Environmental Quality, 1998, 27(6): 1403-1410.

[3] Wang Ke, Zhang Zhijian, Zhu Yinmei et al. Surface water phosphorus dynamics in rice fields receiving fertilizer and manure 
phosphorus. Chemosphere, 2001, 42(2): 209-214.

[4] Sauer TJ, Daniel TC, Nichols DJ et al. Runoff water quality from poultry litter-treated pasture and forest sites. Journal of Environmental Quality, 2000, 29(2): 515-521.

[5] Borovkov VS, Volshanik VV, Lapina NM et al. The effect of nutrient pollution on the quality of water and bottom sediments in the ponds of the Moscow Zoological Park. Water Resources, 2000, 27(2): 189-196.

[6] 章永松, 林咸永, 倪吾钟. 有机肥对土壤磷吸附-解吸的直接影响. 植物营养与肥料学报, 1996, 2(3): 200-205.

[7] Murphy J, Riley P. A modified single solution method for the determination of phosphate on natural water. Analytica Chimica Acta, 1962, 27: 31-36.

[8] Holford ICR, Wedderburn RWM, Mattingly GEG. A Langmuir two-surface equation as a model for phosphate adsorption by soils. Journal of Soil Science, 1974, 25: 242-245.

[9] 南京农业大学主编. 土壤农化分析. 北京: 农业出版社, 1992: 33-36, 80-82.

[10] Dou Z, Toth JD, Galligan DT et al. Laboratory procedures for characterizing manure phosphorus. Journal of Environmental Quality, 2000, 29(2): 508-514.

[11] Pierson ST, Cabrera ML, Evanylo GK et al. Phosphorus and ammonium concentrations in surface runoff from grasslands fertilized with broiler litter. Journal of Environmental Quality, 2001, 30(5): 1784-1789.

[12] Schepers JS, Francis DD. Chemical water quality of runoff from grazing land in Nebraska: I. Influence of grazing livestock. Journal of Environmental Quality, 1982, 11(3): 351-354.

[13] 鲍士旦主编. 土壤农化分析(第三版). 北京: 中国农业出版社, 2000: 70-71.

[14] Leinweber P, Haumaier L, Zech W. Sequential extractions and ${ }^{31} \mathrm{P}$ NMR spectroscopy of phosphorous forms in animal manures, whole soils and particle size separates from a densely populated livestock area in northwest Germany. Biology and Fertility of Soils, 1997, 25(1): 89-94.

[15] Qian P, Schoenau JJ. Fractionation of P in soil as influenced by a single of liquid swine manure. Canadian Journal of Soil Science, 2000, 80(4): 561-566.

[16] 江锦花, 柯世省, 丁理法等. 围塘养殖沉积物中磷的存在形态、分布及环境效应. 浙江海洋学院学报(自然科学版), 2004, 23(4): 311-314.

[17] 王永和, 曹翠玉, 史瑞和. 有机肥对石灰性土壤无机磷组分的影响. 土壤, 1996, 4: 180-182.

[18] 尹金来, 沈其荣, 周春霖等. 猪粪和磷肥对石灰性土壤无机磷组分及有效性的影响. 中国农业科学, 2001, 34(3): 296-300.

[19] 胡 俊, 吴永红, 刘永定等. 滇池典型区域磷与铁的形态分布规律. 环境化学, 2005, 24(4): 450-453.

[20] Ding-Sie T, Adhityan A. General characteristics and fractions of phosphorus in aquatic sediments of two tropical reservoirs. Water Science and Technology, 1996, 34(7-8): 53-59.

[21] Long N, James S. Phosphorus fractions and retention in drainage ditch sediments receiving surface runoff and subsurface drainage from agricultural catchments in the North Island, New Zealand. Agriculture Ecosystems and Environment, 2002, 92: 49-69.

[22] 章永松, 林咸永, 罗安程等. 有机肥(物)对土壤中磷的活化作用及机理研究 I: 有机肥(物)对土壤不同形态无机磷的活化 作用. 植物营养与肥料学报, 1998, 4(2): 145-150.

[23] 张 敏, 李建秋, 周易勇. 网箱养殖对东湖沉积物有机质含量以及磷的酶促水解与吸附行为的影响. 水产学报, 2002, 26(6): 510-518.

[24] 夏立忠, Roy Anderson. 长期施用牛粪条件下草原土壤磷的等温吸附与解吸动力学. 土壤, 2000, 3: 160-164.

[25] Halford ICR, Hird C, Lawrie R. Effects of animal effluents on the phosphorus sorption characteristics of soils. Australian Journal of Soil Research, 1997, 35(2): 365-373.

[26] Knud-Hansen CF. Pond history as a source of error in fish culture experiments: A quantitative assessment using covariate analysis. Aquaculture, 1992, 105(1): 21-36.

[27] 王圣瑞, 金相灿, 赵海超等. 长江中下游浅水湖泊沉积物对磷的吸附特征. 环境科学, 2005, 26(3): 38-43.

[28] Villapado RR, Graetz DA. Phosphorous sorption and desorption properties of the Spodic Horizon from selected Florida Spodosols. Soil Science Society of America Journal, 2001, 65(2): 331-339. 